To Appear in Australasian Journal of Philosophy 93 (3): 475-90 (2015).

\title{
Toward a Commonsense Answer to the Special Composition Question
}

\author{
CHAD CARMICHAEL
}

\section{Indiana University-Purdue University Indianapolis}

\begin{abstract}
The special composition question is the question 'When do some things compose something?' The answers to this question in the literature have largely been at odds with common sense, either by allowing that any two things (no matter how apparently unrelated) compose something, or by denying the existence of most ordinary composite objects. I propose a new "series-style" answer to the special composition question that accords much more closely with common sense, and I defend this answer from van Inwagen's objections. Specifically, I will argue (among other things) that the proposed answer entails the transitivity of parthood, that it is non-circular, and that it casts some light on the ancient puzzle about the Ship of Theseus.
\end{abstract}

Keywords: composition, parts, objects, common sense

\section{Introduction}

When do some things compose something? This is van Inwagen's (1990) special composition question (SCQ). The most popular answer to this question (universalism) is that composition always occurs: for any (disjoint) objects, there is an object composed of those objects. ${ }^{1}$ Thus, according to this view, there is an object composed of my left pinky and the moon. Meanwhile, the second most popular answer - that composition never occurs - denies the existence of such

1 See, for example, Cartwright (1975), Quine (1981: 10), Thomson (1983: 216-17), Lewis (1986a: 212-13, 1991: §1.3), van Cleve (1986, 2008), Heller (1990: §2.9), Sider (2001: §4.9), Rea (1998), Hudson (2000, 2001: §3.8), Varzi (2005), Bigelow and Pargetter (2006), and Braddon-Mitchell and Miller (2006).

This is the author's manuscript of the article published in final edited form as: Carmichael, C. (2015). Toward a Commonsense Answer to the Special Composition Question. Australasian Journal of Philosophy, 93(3), 475-490. http://doi.org/10.1080/00048402.2014.989397 
objects as chairs, tables, rocks, trees, human beings, and so on. ${ }^{2}$ The so-called "moderate" positions of van Inwagen (1990) and Merricks (2001) allow that composition occurs in the case of human persons, but they deny tables and chairs. Hoffman and Rosenkrantz (1997) allow organisms and what they call mereological compounds: strange composite objects which look just like ordinary objects, but which are incapable of changing parts. They admit that there is something where I thought my chair was. But they too deny tables and chairs and rocks and mountains, since those things could gain and lose parts if they existed. ${ }^{3}$

I will use 'common sense about composition' for the view that the most obvious objects in our immediate environments (e.g., tables, chairs, organisms, and the like) exist, while the extraordinary universalist objects (e.g., pinkymoons) do not. ${ }^{4}$ In this sense, the proposals mentioned above do not accord with common sense about composition. ${ }^{5}$ Although this is a natural way to use the expression 'common sense about composition', nothing substantive depends on this choice of terminology. I will not claim, for example, that accord with common sense about composition is a virtue (although I believe that it is a virtue, I will not rely on this claim). This terminology simply allows me to state my project in a handy way: I will provide a new answer to the SCQ which, unlike any of the proposed answers so far, accords with common sense about composition. ${ }^{6}$

There are two motivations for developing such an answer to the SCQ. First, one of the major reasons that so few philosophers accept a commonsense

2 This view is usually called nihilism. Proponents include Hestevold (1981), Hossack (2000), Dorr (2005), Horgan and Potrč (2008: chapter 7), and Rea (2001).

3 Rosencrantz and Hoffman do not endorse an answer to the SCQ, instead contenting themselves with an ontology of material objects comprising organisms and "mereological compounds", together with an analysis, in mereological terms, of the kinds of unity that are appropriate to each kind of object in the ontology (though see note 19 for an argument that their theory is commited to some unintended results). For their discussion of the SCQ, see (ibid.: chapter 5, §7).

4 Note well that I am speaking English, I am not restricting my attention to a limited domain, I am not speaking loosely or non-literally, and I'm in the philosophy room (though I believe the last point makes no difference).

5 The (stronger) claim that these views are contrary to what almost all ordinary people believe is surprisingly controversial. For example, universalists often claim that ordinary English speakers typically use restricted quantifiers, and that, as a result, ordinary people simply ignore (rather than deny) the unusual objects recognized by the theory. Similarly, nihilists often try to reconcile their view with that of ordinary people by providing elaborate paraphrase strategies. Although nothing I say hinges on the rejection of these attempts at reconciliation, see Korman $(2008,2009)$ for a powerful critique.

6 Markosian's (1998) view may accord with common sense. On this view, when there is a composite object, this cannot be given any informative explanation in terms of a relationship between the relevant composers. However, this is not an answer to the SCQ; rather, it's a theory according to which there are no such (non-trivial) answers. Markosian's more recent (2014) regionalist answer to the SCQ (the xs compose something just in case there is something exactly where the xs are) is also consistent with common sense. However, regionalism is, in addition, consistent with both nihilism and universalism, and thus has little to tell us about which objects there are. Regionalism also faces apparent counterexamples: see Mellor (2008: 68), Williams (2008: §6), Gilmore (2014: §4), and Markosian (2014: 73-74) for discussion. 
view of composition is that they simply do not see how to work one out. ${ }^{7}$ My proposal will show how we might do what these philosophers have thought to be impossible. And, if I am right that the major obstacle to a commonsense view of composition is that no plausible proposal has been forthcoming, the mere articulation of a commonsense answer is dialectically significant, forcing proponents of previously more popular views to rely more heavily on controversial arguments. ${ }^{8}$

Second, the answer that emerges from trying to accommodate common sense about composition is interesting and illuminating, both intrinsically and in the light that the answer casts on traditional puzzles involving composition (such as the Ship of Theseus, as we will see). The proof of the pudding is in the eating, and I will be able to provide only a taste here. But I hope that the taste will leave the reader wanting more.

For these reasons, I will attempt to articulate a commonsense answer to the SCQ. But it turns out that accommodating common sense is a tall order. For, according to the most natural idea of what such an answer might look like, things compose something just in case they're bonded together in some appropriate way. This seems to be the right idea when we think of objects that are welded together (say, a barbeque), or objects that are held together with glue (such as a child's art project). But, as van Inwagen points out (1990: §7), it seems that any simple bonding answer to the SCQ is doomed to falter on examples such as two people glued together at the hand: any such answer will be subject to counterexamples involving bonded organisms, which intuitively (and according to common sense) do not compose something just by being bonded (in any sense of 'bonded').

To fix this problem, what we need is an answer that allows different relations to underlie composition in different cases, so that gluing might make an object when we glue the parts of a model airplane together, but not when we glue the cat to the dog. What is needed, in short, is what van Inwagen calls a seriesstyle answer to the question, which is an answer of the form:

For some $\mathrm{y}$, the $\mathrm{xs}$ compose $\mathrm{y}$ iff the $\mathrm{xs}$ are $\mathrm{F}_{1}$ and stand in $\mathrm{R}_{1}$, or the $\mathrm{xs}$ are $F_{2}$ and stand in $R_{2}$, or ...

Unfortunately, van Inwagen (1990: 61-71) provides several powerful objections to these sorts of answers.

In what follows, I will defend a commonsense, series-style answer to the SCQ that is not subject to any of the difficulties that van Inwagen raises. I will not provide a complete justification of the proposed answer. To do this would require, among other things, a solution for each of the puzzles and arguments about material objects which pose a special difficulty for commonsense approaches: the problem of the many, overdetermination problems, debunking arguments,

\footnotetext{
See, for example, Sanford (1993: 223), Horgan (1993: 694-5), Rosenberg (1997: 704), Thomasson (2007: §7.3), and, as we will see, van Inwagen (1990).

8 In this regard, my project will go beyond Silva (2012), who argues that an answer of the sort I propose can be given, but who does not provide such an answer. Silva's general approach differs substantially from my own.
} 
arbitrariness arguments, and the argument from vagueness. ${ }^{9}$ Instead of addressing all of these problems in a single paper (which would be impossible), I will simply state the answer to the SCQ and defend it from van Inwagen's objections. This will, however, take many important steps in the direction of a complete justification: we will see that the proposed answer entails the transitivity of parthood, that it is non-circular, that it provides an appropriate grounding for facts of composition, and that it illuminates several general issues, including the ancient puzzle about the Ship of Theseus. Furthermore, even in the absence of a complete justification, the proposed answer will make it plausible that the prospects for a commonsense, series-style answer are brighter than many have held.

\section{A Series-Style Answer}

The answer depends on four theses about events. I will set these out in just enough detail to state the answer. I will then return to several of these claims for further justification and defense.

The first thesis is that events are often constituted of the activities of certain objects (cf. van Inwagen (1990: 82-83)). For example, the event which is your life is constituted of the activities of the simples that make you up. ${ }^{10}$ (It is also constituted of the activities of your cells.) And the event associated with a party is constituted of the activities of the revelers, perhaps along with the activities of the simples which make up the venue, the food, and so on. The atmospheric event associated with a given tornado or hurricane will typically be constituted of the activities of lots of pieces of debris, water droplets, and so on. The event associated with a parade is constituted by the activities of the people and objects who participate in the parade. I will assume that this notion is clear enough from these examples for now, although an explicit, non-mereological definition of the notion appears below.

The second thesis about events that I will rely on is that, in some cases, the existence of a composite object is grounded in the occurrence of an underlying event. ${ }^{11}$ For example, the existence of a given organism is grounded in the occurrence of its life, and the existence of a tornado is grounded in the underlying atmospheric event. The organism is not identical to the underlying event: if an organism lives for 100 years, the very same organism might have lived for a far shorter time (say one year). In that case, the 100-year event which is actually the organism's life would not have been its life (this point is due to Plantinga (2006: 9-10)). But, if the event which actually underlies the organism is 100 years long, then the 100 year existence of that organism is grounded in the 100 year occurrence of that event. (Similar remarks apply to tornados and hurricanes,

\footnotetext{
9 The literature on these problems is vast. For an excellent overview of the problems and the various approaches to solving them, see Korman $(2010,2014)$. For my response to the argument from vagueness, see my (2011).

10 I mean 'life' in the narrow biological sense, which is worked out at some length by van Inwagen (1990: §9).

11 I won't say much about grounding here. See the papers in Correia and Schnieder (2012) for discussion.
} 
which I take to be non-events which are grounded in underlying atmospheric events for exactly this reason.)

The third thesis about events I will need is that, when an object's existence is grounded in the occurrence of a given event, the event that underlies the object often imposes a kind of unity on the objects whose activities constitute the event. In these cases, the objects whose activities constitute the event are parts of the object whose existence is grounded in the occurrence of that event. ${ }^{12}$ For example, my existence is grounded in the occurrence of my life, which is constituted of the activities of certain simples. This event imposes a kind of unity on those simples, which makes it natural to say that the simples are parts of me.

Not every event seems to impose an object-generating sort of unity on its participants. For example, consider a conversation. Although our activities may constitute a conversation, it is implausible that there is an object which arises from this event, and which has you and me as parts. Our involvement in the conversation does not require us to be unified in a way that would make each of us parts of a larger whole. Events that give rise to objects composed of their participants are events that (as I will say) impose sufficient unity on their participants. I will propose a (non-mereological) definition of this notion below. For now, it is enough to point out that we are fairly good at distinguishing events that impose sufficient unity, such as my life, from events that do not impose sufficient unity, such as a conversation.

My fourth thesis about events is this: for some composite objects, there is no underlying event at all. For example, in the case of an object like a rock, there does not seem to be an underlying event which unifies its parts. Objects such as rocks aren't event-based, but are instead lump-like. I will say more about this notion of lump-likeness below (I will provide both a definition and an argument that, on any of a number of well-known theories of events, there must be lumplike objects in my sense). Here I just want to point out that there is an intuitive distinction between the objects which are event-based and those which are lumplike.

With these theses in place, the proposed series-style answer to the SCQ can be stated as follows:

Necessarily, for all xs, there is a y such that the xs compose y iff either

(i) the xs are lump-like and the xs are bonded, or

(ii) the activities of the xs constitute an event that imposes sufficient unity on the xs. ${ }^{13}$

Some examples will illustrate how the answer works. A model airplane is composed of several pieces of balsa wood which are glued together. This is

12 This may not be the only way in which the existence of an object can be grounded in the occurrence of an event.

13 For this answer to have the official form of a series-style answer, (ii) would have to read: the xs are self-identical and their activities constitute an event that imposes sufficient unity on them. Also, to secure the reflexivity of parthood, we would have to add: 'or (iii) there is exactly one of the xs.' 
because the pieces of wood (and the various clumps of glue) are lump-like and bonded together, and so compose an object by condition (i). But two people glued at the hand do not compose anything. For people are not lump-like-they are event-based objects, as discussed above-and so do not meet condition (i). And merely gluing together the hands of two people does not result in an event which imposes sufficient unity on them. So they do not meet condition (ii) either. In a hurricane, on the other hand, there are water droplets, quantities of air, debris, and so on, whose activities constitute the relevant atmospheric event. The event in question imposes sufficient unity on these objects. Thus, by condition (ii), these objects compose the hurricane.

\section{Six Objections}

Van Inwagen presses about six objections (depending on how one counts) to answers of the sort I have proposed. I shall respond to each one in turn.

\subsection{The No Proposals Objection}

According to this objection, nobody has ever proposed a reasonable-sounding series-style answer that accommodates common sense, and any such answer is sure to be 'disgracefully messy' in the sense that it would be 'so complex that only God could know it' (1990: 66-8). The articulation of my answer, which is humanly accessible and not in any sense 'disgracefully messy', rebuts this objection.

\subsection{The Transitivity Objection}

One of van Inwagen's two main objections concerns the transitivity of parthood (a "nonnegotiable feature of parthood"). The worry is that, if we give a series-style answer to the SCQ, then if $\mathrm{x}$ is among some $\mathrm{xs}$ that compose $\mathrm{y}$ in virtue of satisfying one disjunct of the definition, and $\mathrm{y}$ is among some ys that compose $\mathrm{z}$ in virtue of satisfying another disjunct of the definition, then $\mathrm{x}$ will be a part of $\mathrm{y}$, and $\mathrm{y}$ will be a part of $\mathrm{z}$, but $\mathrm{x}$ will not be a part of $\mathrm{z}$.

Van Inwagen's worry makes sense if the different disjuncts specify different but unrelated kinds of bond. For example, suppose we said that Gs can only compose something by being glued together, while Ws can only compose something by being welded together. Then suppose that we glue together some Gs to make a $\mathrm{W}$, and we glue together some other Gs to make another $\mathrm{W}$. Then suppose that we weld the two Ws together to make an object $O$. In this case, the Gs will be parts of the Ws, and the Ws will be parts of O, but, because the Gs are not all glued to each other-some only being connected to others by way of the weld connecting the two Ws-it follows that the Gs will not be parts of $\mathrm{O}$, in violation of transitivity.

Fortunately, the relations that feature in my proposal are more closely related than gluing and welding, as we will now see. Given my proposed answer 
to the SCQ, there are two ways in which one might try to construct a counterexample to transitivity:

First way: one might try to describe a case in which some objects, the xs, compose something in virtue of the fact that the activities of the xs constitute a unity-imposing event, but some part of one of the xs is not among some objects whose activities constitute that event.

Second way: one might try to describe a case in which some objects, the xs, compose an object in virtue of the fact that the xs are lump-like and bonded, but some part of one of the xs is not among some things that compose the relevant object.

I will argue that neither sort of counterexample is possible, and that my answer to the SCQ therefore entails transitivity.

Consider the first way. Such counterexamples are intuitively impossible: something can't be "caught up" in an event without its parts being "caught up" in the event as well. More exactly:

(T) If the activities of the xs constitute e, and y is part of one of the xs, then there are some zs such that the activities of the zs constitute e and $\mathrm{y}$ is among the $\mathrm{zs}$.

For example, if the activities of my cells constitute my life, and some simple is a part of one of those cells, then that simple is among some things (the simples that compose me) whose activities constitute my life.

(T) is plausible in its own right. However, there is also an argument for (T) that proceeds from a definition of event constitution, together with two plausible premises. Here is the definition of event constitution:

(C) The activities of the xs constitute event e iff df $_{\text {the fact that e occurs }}$ is grounded in facts about the activities of the xs. ${ }^{14}$

Thus, when an event is constituted of the activities of some things, its occurrence is grounded in facts about those things. Now suppose that some event $\mathrm{e}$ is constituted of composite objects $x_{1}, \ldots, x_{n}$. Then, by (C), the occurrence of e is grounded in facts about $\mathrm{x}_{1}, \ldots, \mathrm{x}_{\mathrm{n}}$. Now for the first premise: the facts about a composite object are grounded in facts about its parts. ${ }^{15}$ Given this premise, it

14 It can perhaps be left open exactly what counts as an activity in the relevant sense. Principally, I have in mind facts about spatiotemporal locations over time.

15 This includes facts about the extrinsic properties of the composite, which are grounded in facts about the extrinsic properties of its parts. The premise is an analogue (for grounding) of mereological supervenience. Proponents of the latter thesis include Kim (1984), Horgan (1982), Zimmerman (1997), Markosian (2005), and Koslicki (2008). Strictly speaking, a weaker premise suffices for my argument: if some facts about the activities of a composite object $\mathrm{x}$ partially ground the occurrence of event $\mathrm{e}$, then these facts about $\mathrm{x}$ are grounded in facts about the parts of x. Even Schaffer (2010), who would reject the stronger premise, could 
follows that the facts about $x_{1}, \ldots, x_{n}$ which ground the occurrence of e are themselves grounded in the parts of $x_{1}, \ldots, x_{n}$. Now the second premise: grounding is transitive. ${ }^{16}$ Given this premise, since the occurrence of $e$ is grounded in facts about $\mathrm{x}_{1}, \ldots, \mathrm{x}_{\mathrm{n}}$, and those facts are in turn grounded in facts about the parts of $x_{1}, \ldots, x_{n}$, it follows that the occurrence of $e$ is grounded in facts about the parts of $x_{1}, \ldots, x_{n}$. By (C), it follows that the parts of $x_{1}, \ldots, x_{n}$ constitute event e. Thus, if an event is constituted of $x_{1}, \ldots, x_{n}$, it is constituted of the parts of $\mathrm{x}_{1}, \ldots, \mathrm{x}_{\mathrm{n}}$. This, in turn, is equivalent to $(\mathrm{T})$.

The second way of generating a counterexample also seems to be impossible. And, additionally, this can be shown by way of an argument that proceeds from the transitivity of bonding (which is itself guaranteed by the definition of bonding that appears below). For suppose that $\mathrm{x}_{1}, \ldots, \mathrm{x}_{\mathrm{n}}$ are lumplike and bonded, and that they compose object $\mathrm{O}$. And suppose that $\mathrm{y}_{1}$ is among some objects $\mathrm{y}_{1}, \ldots, \mathrm{y}_{\mathrm{n}}$ which are lump-like and bonded, and which compose $\mathrm{x}_{1}$. Could $\mathrm{y}_{1}$ fail to be a part of O? No. For $\mathrm{x}_{1}$ is composite and bonded to the rest of O. And, if a composite is bonded to something, then some part of that composite is bonded to that thing. So there is some part of $x_{1}$-let it be $y_{2}$ - which is bonded to the rest of $\mathrm{O}$. But, by hypothesis, all the parts of $\mathrm{x}_{1}$, including $\mathrm{y}_{2}$, are bonded to each other. Since bonding is transitive, all the parts of $\mathrm{x}_{1}$ are therefore bonded to $\mathrm{x}_{2}, \ldots, \mathrm{x}_{\mathrm{n}}$. By my proposed answer to the SCQ, this is sufficient for $\mathrm{y}_{1}, \ldots, \mathrm{y}_{\mathrm{n}}$ (i.e., the parts of $\mathrm{x}_{1}$ ) together with $\mathrm{x}_{2}, \ldots, \mathrm{x}_{\mathrm{n}}$, to compose something. And it is extremely implausible to suppose that they compose anything other than $\mathrm{O}\left(\mathrm{x}_{2}\right.$, $\ldots, \mathrm{x}_{\mathrm{n}}$ are, after all, parts of $\mathrm{O}$, and $\mathrm{y}_{1}, \ldots, \mathrm{y}_{\mathrm{n}}$ compose $\mathrm{x}_{1}$, the remaining part of $\mathrm{O})$. Thus, $\mathrm{y}_{1}$ is a part of $\mathrm{O}$.

Given my answer to the SCQ, there are only two possible counterexamples to transitivity. Each kind of counterexample is impossible, both intuitively and in light of the above arguments. As a result, transitivity follows, and van Inwagen's transitivity objection fails.

\subsection{The Circularity Objection}

This is van Inwagen's other main objection. The idea of this objection is that the terms in my proposed answer-'bonded', 'lump-like', 'the activities of the xs constitute event e', and 'sufficient unity'-are covertly mereological in nature. Van Inwagen seems to allow (1990: 64-5) that there could theoretically be a series-style answer that avoids this problem, but he claims that any such answer would have to invoke unity relations (relations that play the role which bonding and event-based unity play in my answer) which hold between some xs only if the xs compose something. If this were true, it would undermine the intuitive motivation for giving a series-style answer, namely, that relations like bonding can bring about composition in some cases but not others. He thus presents his

accept this weaker premise, since his monism is explicitly restricted [ibid.: 33) to exclude such things as events.

16 Proponents of this premise include Schaffer (2009), Fine (2010), Correia (2010), Whitcomb (2012), and Cameron [forthcoming]. For some alleged counterexamples, see Schaffer (2012). For replies, see Raven (2013) and Litland (2013). 
challenge as a dilemma: any series-style answer will either be circular or it will fail to serve the intuitions which motivated it in the first place.

The unity relations that my answer invokes are intuitively capable of relating more or less any material objects (e.g., sharks can be glued together and they can also be caught up in a tornado together). I will therefore embrace the first horn of van Inwagen's dilemma by giving non-mereological definitions of the relevant terms such that, so interpreted, my proposed answer to the SCQ remains consistent with common sense. Such a definition of 'the activities of the xs constitute event e' appears as principle (C) above. ${ }^{17}$ I will now provide such definitions for the other terms as well.

First, I define 'e imposes sufficient unity on the xs' as follows:

e supposes sufficient unity on the xs iff $f_{\mathrm{df}}$

(i) the activities of the xs constitute e;

(ii) e is self-sustaining: earlier stages of e cause later stages of e;

(iii) e is homeodynamic: possibly, there are xs such that the activities of the xs constitute e at one time, but none of the xs participates in e at another time (at which e occurs).

Additionally, I define 'x participates in e', as it occurs in (iii), as follows:

$\mathrm{x}$ participates in e iff $\mathrm{df}_{\mathrm{f}}$, for some $\mathrm{ys}, \mathrm{x}$ is among the $\mathrm{ys}$, and the activities of the ys constitute e.

My life, together with the simples whose activities constitute it, meets conditions (i) - (iii) in the above definition of 'sufficient unity'. Therefore, my life imposes sufficient unity on the simples whose activities constitute it. And here are some further examples of events which, together with their participants, seem to meet the conditions: the spread of a fire, the movement of a wave across the water, the atmospheric event associated with the red spot on Jupiter, and the movement of an avalanche down the surface of the mountain.

However, many events are not like these. For example, no event which is instantaneous can meet condition (iii), since a change in participants would have to occur over an extended interval of time. Nor in at least many cases can very short events be homeodynamic. The reason is that, in such an event, replacement of participants cannot be gradual (since gradual replacement takes too long). But, in many cases at least, events intuitively cannot persist through a non-gradual replacement of participants. Thus, consider a typical window-breaking. Such an event is too short to undergo a complete change in participants in the way required to count as homeodynamic; a relatively quick change in all the particles making up the window during the break seems to involve the replacement of the original window with a different window, and thus seems to bring about a different event: the breaking of a different window. A typical window-breaking, then, does not meet condition (iii), and does not impose sufficient unity on its

\footnotetext{
${ }^{17}$ Van Inwagen himself cannot say that 'the activities of the xs constitute event e' is implicitly circular, as his own answer to the SCQ utilizes this notion of event constitution.
} 
participants. And the same sort of point can be made about collisions generally, as well as: explosions, births, deaths, thunder claps, milk spillings, tree fallings, and so on.

Another broad category of events that seem not give rise to event-based objects is the category of actions of individuals. Sometimes this is true for the reasons given above: an action is simply too momentary to be homeodynamic (think here of a single clap of the hands). But it is also true that no objects emerge from temporally extended actions of individuals. For example, suppose Frank Sinatra is singing a song. The event of his singing is not a self-sustaining event: Sinatra himself (or events in him that are not stages of the singing event) causes the later stages of the song; the earlier stages do not cause the later. ${ }^{18}$ Thus, this singing event does not impose sufficient unity on its participants. And the same goes for the actions of individuals generally: actions are sustained by their agents rather than by their earlier stages.

A number of natural events fail condition (ii). For example, consider the erosion of a given rock. Later stages of the erosion are not caused by earlier stages of the erosion. Rather, later stages are caused by the same natural forces external to the rock that caused earlier stages. Similar points can be made about the rusting of a piece of metal, the melting of a piece of ice, the extended appearance of a rainbow, the rise of the tide, and so on.

The definition I have provided of 'e imposes sufficient unity on the xs' is not adequate to settle every controversy about whether a given event imposes sufficient unity. However, I think that the above discussion does show that the definition I provided renders the concept serviceable.

Next, I will provide a non-mereological definition of 'lump-like'. Above, I claimed that an event that grounds the existence of an object often does so by imposing sufficient unity on its composers. Specifically, the idea is that:

(E) If the fact that $\mathrm{x}$ exists is grounded in the fact that e occurs, and there are some ys such that the ys compose $\mathrm{x}$ and all and only the ys participate in e, then e imposes sufficient unity on the ys.

This principle will be useful in justifying the following definition:

$\mathrm{x}$ is lump-like $\operatorname{iff}_{\mathrm{df}} \mathrm{x}$ is a material object and there is no event e such that the fact that $\mathrm{x}$ exists is grounded in the fact that e occurs.

I am not a lump-like object because my existence is grounded in the occurrence of a certain event: my life. But this rock is a lump-like object, because there is no such event associated with it. If the xs compose the rock, then perhaps there is an event of the xs being bonded. However, the occurrence of this event does not

18 In many cases, the later stages of an action will counterfactually depend on earlier stages. However, the relevant counterfactuals are what Lewis (1979: 456-8) calls 'backtracking counterfactuals'. This is the sort of counterfactual dependence that holds when two events, neither of which causes the other, have a common cause. Lewis's own theory disregards this sort of dependence as non-causal (as it should). 
ground the fact that the rock exists. For, by (E), if this event did ground the fact that the rock existed, the event would have to impose sufficient unity on the composers of the rock. But it does not, since the relevant event in this case is not homeodynamic.

That there are lump-like objects in this sense is a commitment of a common view about events: that the existence of a material object is not always grounded in the fact that some event occurs. This is plausible in its own right, but it is also a commitment of most known theories of events, such as those developed by, for example, Davidson (1969), Kim (1976), Lewis (1986b], Lombard (1986), and Bennett (1988). All of these theories of events entail that events have participants on which they depend. Thus, assuming that chains of dependence must end, it follows that there are events which depend, not on further events, but on non-event participants (typically, material objects of one kind or another).

What about 'bonded'? Following Hoffman and Rosenkrantz (1997, chapter 3), we may define this expression in terms of the relation that they call dynamic equilibrium: roughly, the relation that holds between two things between which there is a balance of attractive and repulsive forces. Given this notion, they define the joining relation as the relation that holds between two material objects when (i) either object is such that it is physically possible to push or pull it in any direction by correspondingly moving the other object and (ii) this is in virtue of the relation of dynamic equilibrium holding between them. Given these ideas, we may now define bonding as follows:

The xs are bonded iff $f_{d f}$ the xs are related by the ancestral of the joining relation on the xs. ${ }^{19}$

In light of these definitions of the key terms in the proposed answer, I think it is plausible that the answer is not circular in any objectionable sense. Therefore, the circularity objection fails.

\subsection{The Grounding Objection}

Suppose it is a fact that a given model airplane is composed of pieces of wood $\mathrm{w}_{1}$, $\ldots, \mathrm{w}_{\mathrm{n}}$. According to the proposed series-style answer, this fact is grounded in the fact that $\mathrm{w}_{1}, \ldots, \mathrm{w}_{\mathrm{n}}$ are bonded to one another. But, if bonding some objects together is sufficient to ensure that they compose something in this case, why

19 This definition differs from that offered by Hoffman and Rosencrantz (1997: 86), who say that some objects are bonded (their expression is "joined and connected") iff ${ }_{\mathrm{df}}$ each of the objects (or a part thereof) is joined to every other object (or a part thereof) in such a way that a path can be traced from the one to the other. Their definition is unsuitable for my purpose, since it invokes parthood. Their definition is also unsuitable for their purposes. For it entails that, if a part of one organism is joined to a part of another, then the organisms are bonded. Hoffman and Rosencrantz claim that, if two things are bonded, then there is something they compose. They are thus committed to the conclusion that bonded organisms compose something, which, aside from being implausible, is at odds with various other theses that they accept. 
would being bonded not have the result that two persons compose something if they are joined at the hand? In other words, what is the difference between pieces of wood and organisms, such that bonding has the power to cause the former, but not the latter, to compose something? If we are unable to answer this question, doubt is cast on the distinction that the answer draws.

Here is my reply. Parthood is transitive. Therefore, in order to cause $\mathrm{x}$ and $\mathrm{y}$ to compose something, one must bring it about that all the parts of $\mathrm{x}$ and $\mathrm{y}$ stand in a composition-inducing relation to one another. Given the proposed answer to the SCQ, bonding does this in the case of pieces of wood: when two pieces of wood are bonded together, all the parts of each piece are bonded to all the other parts of both pieces. But, when two organisms are bonded, the parts of those organisms are not all bonded to one another. Indeed, when two organisms are bonded, it is false that any composition-inducing relation recognized by the proposed answer holds among all the parts of both organisms. So, if the proposed answer is true, there is a relevant difference between lump-like objects and eventbased objects. The present objection claims that the proposed answer has no way to identify such a difference. Thus, this objection fails.

\subsection{The First Inadequacy Objection}

Van Inwagen presses two objections to the effect that no series-style answer could adequately illuminate the issues about composition that lead us to an interest in answering the SCQ in the first place. The first of these objections is that a seriesstyle answer has to be designed to fit our pre-theoretic opinions about what exists rather than informing those opinions. In particular, the relations invoked in each disjunct (in my answer, the relation of being bonded and the relation of jointly constituting an event of the right sort) will be specifically selected to generate a common sense ontology. Thus, common sense opinion about what exists guides us to our answer rather than our answer telling us what our opinions should be about what exists. This is a problem, van Inwagen claims, because it "would be nice if we had an answer that had something to tell us about what objects there were" (1990: 66).

It is true that the series-style answer I have proposed was developed specifically to accommodate common sense. For example, my proposal is specifically designed to accommodate the commonsense view that chairs and tables and cats exist, but that no object is composed of a cat and a table (even if the cat is on the table, and even if the cat is lying in a puddle of strong glue). However, contrary to van Inwagen, I believe that this is ontologically illuminating in two different ways.

First, because no commonsense answer to the SCQ has been forthcoming, some (see note 7) have held that a commonsense answer to the question is impossible. This might suggest that common sense is mistaken about what sorts of material objects exist. The fact that my answer generates a commonsense ontology of material objects therefore undermines this source of skepticism about commonsense ontology, thereby taking a significant step toward justifying this 
ontology. In this sense, it does have "something to tell us" about what objects exist.

Second, the proposed series-style answer to the SCQ invokes two general categories of material objects: the lump-like objects, on the one hand, and the event-based objects, on the other. I believe that this distinction reveals a deep fact about the nature of material objects, and (as we will see below) that this fact will be helpful in making progress on various puzzles about material objects. Thus, I think that the proposed series-style answer does have something useful and illuminating to tell us about what sorts of material objects exist, since it tells us that there are two kinds of material object: lump-like objects and event-based objects. The idea that all material objects fall into these categories is not, I think, a commitment of common sense. Rather, this is an interesting consequence of a theory which was designed to accommodate common sense. Thus, it serves as an example of how attempting to accommodate common sense can lead to a deeper understanding of the nature of the phenomenon at hand.

Given that the proposed answer both helps to justify the commitments of common sense and also helps to understand those commitments, it seems to me mistaken to suggest that the proposed answer has "nothing to tell us" about what material objects exist. The first inadequacy objection therefore fails.

\subsection{The Second Inadequacy Objection}

This objection is that no series-style answer will have anything helpful to say about how to deal with the familiar puzzles about the persistence of material objects: the Ship of Theseus, the puzzles of personal identity, and the puzzle of how a material object can persist through a complete change in material parts. My proposed answer suggests a clear solution to this last problem: people and other organisms survive the complete replacement of the material parts that compose them because their continued existence as composite objects depends not on the identity of the material things that make them up, but rather on the continued occurrence of the homeodynamic event-their life-which imposes unity on those material things. Furthermore, my answer also has something to offer in the case of the Ship of Theseus, as I will now discuss. ${ }^{20}$ The key idea here will be the fact that my proposed answer depends crucially on the distinction between eventbased and lump-like objects, and these notions very plausibly have built-in persistence conditions.

In the Ship of Theseus case, a ship (the Original Ship) sets out to sea. While at sea, all of the parts that originally composed the ship are very slowly replaced with new parts. At the end of this long replacement process, we have a ship we may call the Mended Ship. Meanwhile, the original parts are gathered together and reassembled into their original form (the Reassembled Ship). Which of the two ships at the end of the story (if either) is identical to the Original Ship?

From the perspective of my proposed series-style answer, some of the uncertainty we feel about this case is a result of the fact that the case is under-

20 The complex issues about personal identity will have to remain unaddressed here, but I will note that I believe the proposed answer can help in this area as well. 
described. For example, if we suppose that the ship is a living thing (which would be unusual, but does seem to be possible), and we suppose that my proposed series-style answer is correct, the uncertainty vanishes: it becomes very natural to identify the Original Ship with the Mended Ship. On the other hand, if we specify that the ship is lump-like-say, a hollowed tree trunk formed by natural forces and simply found by its owner-then proponents of my series-style answer to the SCQ will be much more strongly inclined to think that the Original Ship is identical to the Reassembled Ship. This is because it is extremely plausible that, if you start with a hunk of wood, and you end with an exactly similar hunk of exactly the same wood, in exactly the same state, then the hunk with which you started is identical to the hunk with which you ended. ${ }^{21}$ (Of course this is just a sufficient condition for identity of lump-like objects. It is not necessary, as a rock can lose a molecule and remain the same rock.)

But what if the ship is just an ordinary ship: not a naturally hollowed-out tree trunk or a strange ship-shaped living thing, but a regular ship made of wood planks and beams and canvas and steel? Let's call this the puzzle of the Ordinary Ship of Theseus. If my proposal has been correct, the puzzle of the Ordinary Ship of Theseus can be solved by determining whether ordinary ships are event-based objects whose identities are determined by their underlying events, or whether we should instead regard ordinary ships as lump-like objects, whose identities might be ensured by the identity and arrangement of their composers.

In order to see whether the theory I have proposed has anything helpful to say about the puzzle of the Ordinary Ship of Theseus, let's assume that my theory is correct. (This is an appropriate assumption, given that the present objection is that the theory, if true, would not be illuminating about these sorts of puzzles.) To suggest that the Ordinary Ship of Theseus is an event-based object, one would need to posit an event that is closely analogous to the life of an organism-an event such as what van Inwagen calls the ship's "history of maintenance" (1990: 135ff.]. Let's suppose for the sake of argument that there is such an event as this. Would such an event meet the conditions required for being an event which imposes sufficient unity on the parts of the ship?

I think not: the "history of maintenance" is not a self-sustaining event. For it seems that the most salient causal factors that lead to the later stages of the event are not its earlier stages, but rather events that are entirely "outside" of the history itself: the intentions, thoughts, and budget of the ship owner, for example. I will not rest anything on this point, though, as it seems clear that a ship's history of maintenance does not meet the first criterion for being an event that imposes sufficient unity on the parts of the ship: the activities of the parts of the ship do not constitute the history of maintenance.

To see this, first note that certain activities of the shipwright—his repair of the mast, his replacement of that rotten board, and so on-are a part of what constitutes the history of maintenance for a given ship. These activities are in

21 I find it plausible in this case to describe the ship as lump-like, but certain colocationists may deny that the hollowed out tree trunk could become a ship. Such colocationists will (to me, implausibly) regard the hunk of wood as colocated with a ship that began to exist at around the time the hunk of wood was put into service. 
some way analogous to various processes in a living body, such as (for example) the activities of various cells involved in wound healing. But although the shipwright is clearly a participant in the history of maintenance in this case, the shipwright would not thereby be among the objects which compose the ship, as it is a very unusual sort of ship that has a shipwright as a part. What seems to be going wrong is this: while the shipwright does seem to be participating in the history of maintenance for the ship, this history is not what grounds the existence of the ship. The history of maintenance certainly plays a causal role in the continued existence of the ship, but it does not ground its continued existence. In this way, the history of maintenance for a ship is not the same as the life of an organism: it does not impose the same kind of unity on its participants, as it involves participants which are not parts of the ship. ${ }^{22}$

For these reasons, the answer I have proposed to the SCQ suggests that, in the case where the Ship of Theseus is a normal ship, the Original Ship is not an event-based object. It may of course superficially appear to be an event-based object, since the history of maintenance for a ship superficially appears to be similar to events of the sort which underlie organisms and other event-based objects. To the degree that this appearance is present in the reactions of those puzzled by the case, my account provides an explanation of what was puzzling about the case in the first place. But, in any case, if my proposal is correct, it seems that we should identify the Original Ship with the Reassembled Ship (if we identify it with either of the ships that exist at the end of the story). ${ }^{23}$

My discussion of the Ship of Theseus has proceeded on the assumption that the proposed answer is correct. This is because van Inwagen's objection was that, if such an answer were correct, it would cast no light on such puzzles as the Ship of Theseus. The foregoing discussion should make it clear that van Inwagen was mistaken about this.

\section{Conclusion}

We have seen that there is no in principle difficulty with common sense answers of the sort that I favor. Secondarily, we have seen that, at least in the case of the SCQ, attempting to accommodate common sense can be a fruitful and illuminating enterprise. The proposed answer still faces various puzzles and

22 This shows that, if there is such a thing as the history of maintenance for a given ship, this event does not impose sufficient unity on the parts of the ship. But does the history of maintenance impose sufficient unity on a wider class of objects that includes the ship, the shipwright, his tools, and perhaps other things? If there is such an event, we should be skeptical that it is self-sustaining for the reasons mentioned before. In addition, proponents of a common sense view of material objects will naturally also wish for a common sense view of events. Plausibly, such a view of events should not admit events that are constituted partly of the activities of the ship and partly of the activities of the shipwright's hammer. To insist on the existence of such an event in this context, then, seems to beg the question against commonsense accounts.

23 Related sorites puzzles still remain, such as the question whether there is an exact moment at which the Original Ship is replaced with the Mended Ship. However, sorites puzzles are puzzling to everyone, and do not seem to be specifically about composition. 
arguments (mentioned in the introduction) which I have not discussed. Additionally, there are some composite material objects which are recognized by common sense, but which are not accommodated by the proposal. For example: piles of sand, arrangements of furniture, constellations, and so on. These problems will remain unsolved here. ${ }^{24}$

\section{References}

Bennett, Jonathan. 1988. Events and Their Names. Clarendon Press.

Bigelow, John and Robert Pargetter. 2006. Real Work for Aggregates. Dialectica 60: 485-503.

Braddon-Mitchell, David and Kristie Miller. 2006. Talking about a Universalist World. Philosophical Studies 130: 499-534.

Carmichael, Chad. 2011. Vague Composition without Vague Existence. Nous 45: 315-27.

Cameron, Ross. Forthcoming. Truthmakers. In The Oxford Handbook of Truth, ed. Michael Glanzberg. Oxford University Press.

Cartwright, Richard. 1975. Scattered Objects. In Analysis and Metaphysics, ed. Keith Lehrer. D. Reidel Publishing Company: 153-71.

Correia, Fabrice. 2010. Grounding and Truth-Functions. Logique et Analyse 53: 251-79.

Correia, Fabrice and Benjamin Schnieder. 2012. Metaphysical Grounding: Understanding the Structure of Reality. Cambridge University Press.

Davidson, Donald. 1969. The Individuation of Events. In Essays in Honor of Carl G. Hempel, ed. Nicholas Rescher. D. Reidel Publishing Company: 21634.

Dorr, Cian. 2005. What We Disagree About When We Disagree About Ontology. In Fictionalism in Metaphysics, ed. Mark Kalderon. Oxford University Press: 234-86.

Fine, Kit. 2010. Some Puzzles of Ground. Notre Dame Journal of Formal Logic 51: $97-118$.

Gilmore, Cody. 2014. Location and Mereology. The Stanford Encyclopedia of Philosophy (Spring 2014 Edition), ed. Edward N. Zalta.

Heller, Mark. 1990. The Ontology of Physical Objects: Four-Dimensional Hunks of Matter. Cambridge University Press.

Hestevold, H. Scott. 1981. Conjoining. Philosophy and Phenomenological Research 41: 371-85.

Hoffman, Joshua and Gary S. Rosenkrantz. 1997. Substance: Its Nature and Existence. Routledge.

Horgan, Terence. 1982. Supervenience and Microphysics. Pacific Philosophical Quarterly 63: 29-43.

24 Thanks to several anonymous referees for AJP, and special thanks to Dan Korman. 
Horgan, Terence. 1993. On What There Isn’t. Philosophy and Phenomenological Research 53: 693-700.

Horgan, Terence and Matjaž Potrč. 2008. Austere Realism: Contextual Semantics Meets Minimal Ontology. MIT Press.

Hossack, Keith. 2000. Plurals and Complexes. British Journal for Philosophy of Science 51: 411-43.

Hudson, Hud. 2000. Universalism, Four Dimensionalism, and Vagueness. Philosophy and Phenomenological Research 60: 547-60.

Hudson, Hud. 2001. A Materialist Metaphysics of the Human Person. Cornell University Press.

Kim, Jaegwon. 1976. Events as Property Exemplifications. In Action Theory, eds. Myles Brand and Douglas Walton. D. Reidel Publishing Company: 15977.

Kim, Jaegwon. 1984. Concepts of Supervenience. Philosophy and Phenomenological Research 45: 153-76.

Korman, Daniel. 2008. Unrestricted Composition and Restricted Quantification. Philosophical Studies 140: 319-34.

Korman, Daniel. 2009. Eliminativism and the Challenge from Folk Belief. Nous 43: 242-64.

Korman, Daniel. 2010. The Argument from Vagueness for Unrestricted Composition. Philosophy Compass 5: 891-901.

Korman, Daniel. 2014. Ordinary Objects. The Stanford Encyclopedia of Philosophy (Spring 2014 Edition), ed. Edward N. Zalta.

Koslicki, Kathrin. 2008. The Structure of Objects. Oxford University Press.

Lewis, David. 1979. Counterfactual Dependence and Time's Arrow. Nous 13: 455-76.

Lewis, David. 1986a. On the Plurality of Worlds. Blackwell.

Lewis, David. 1986b. Events. In Philosophical Papers, Volume 2. Oxford University Press: 241-69.

Lewis, David. 1991. Parts of Classes. Blackwell.

Litland, Jon. 2013. On Some Counterexamples to the Transitivity of Grounding. Essays in Philosophy 14: 19-32.

Lombard, Lawrence. 1986. Events: A Metaphysical Study. Routledge.

Markosian, Ned. 1998. Brutal Composition. Philosophical Studies 92: 211-49.

Markosian, Ned. 2005. Against Ontological Fundamentalism. Facta Philosophica 7: 69-84.

Markosian, Ned. 2014. A Spatial Approach to Mereology. In Mereology and Location, ed. Shieva Kleinschmidt. Oxford University Press: 69-90.

Mellor, D. H. 2008. Micro-Composition. Royal Institute of Philosophy Supplement 83: 65-80.

Merricks, Trenton. 2001. Objects and Persons. Oxford University Press.

Plantinga, Alvin. 2006. Against Materialism. Faith and Philosophy 23: 3-32.

Quine, W. V. 1981. Theories and Things. Harvard University Press.

Raven, Michael. 2013. Is Ground a Strict Partial Order? American Philosophical Quarterly 50: 191-9. 
Rea, Michael. 1998. In Defense of Mereological Universalism. Philosophy and Phenomenological Research 58: 347-60.

Rea, Michael. 2001. How to be an Eleatic Monist. Philosophical Perspectives 15: 129-51.

Rosenberg, Jay. 1997. Comments on Peter van Inwagen's Material Beings. Philosophy and Phenomenological Research 53: 701-8.

Sanford, David. 1993. The Problem of the Many, Many Composition Questions, and Naïve Mereology. Nous 27: 219-28.

Schaffer, Jonathan. 2009. On What Grounds What. In Metametaphysics: New Essays on the Foundations of Ontology, eds. David Chalmers, David Manley, and Ryan Wasserman. Oxford University Press: 347-83.

Schaffer, Jonathan. 2010. Monism: The Priority of the Whole. Philosophical Review 119: 31-76.

Schaffer, Jonathan. 2012. Grounding, Transitivity, and Contrastivity. In Correia and Schnieder (2012): 122-38.

Sider, Theodore. 2001. Four-Dimensionalism. Oxford University Press.

Thomasson, Amie. 2007. Ordinary Objects. Oxford University Press.

Thomson, Judith Jarvis. 1983. Parthood and Identity Across Time. The Journal of Philosophy 80: 201-20.

Van Cleve, James. 1986. Mereological Essentialism, Mereological Conjunctivism, and Identity Through Time. Midwest Studies in Philosophy 11: 141-56.

Van Cleve, James. 2008. The Moon and Sixpence: A Defense of Mereological Universalism. In Contemporary Debates in Metaphysics, eds. Theodore Sider, John Hawthorne, and Dean W. Zimmerman. Blackwell: 321-40.

Van Inwagen, Peter. 1990. Material Beings. Cornell University Press.

Varzi, Achille. 2005. Change, Temporal Parts, and the Argument From Vagueness. Dialectica 59: 485-98.

Whitcomb, Dennis. 2012. Grounding and Omniscience. In Oxford Studies in Philosophy of Religion Volume 4, ed. Jon Kvanvig. Oxford University Press: 173-201.

Williams, J. R. G. 2008. Working Parts: Reply to Mellor. Royal Institute of Philosophy Supplement 83: 81-106.

Zimmerman, Dean. 1997. Immanent Causation. Philosophical Perspectives 11: 433-71. 